\title{
Combination of preoperative CEA and CA I9-9 improves prediction outcomes in patients with resectable pancreatic adenocarcinoma: results from a large follow-up cohort
}

\author{
OncoTargets and Therapy \\ 24 February 2017 \\ Number of times this article has been viewed
}

\author{
Guofeng Zhou, ${ }^{1,2, *}$ Xiaoyu \\ Liu, ${ }^{1-4, *}$ Xiaoyi Wang, ${ }^{5, *}$ \\ Dayong Jin, ${ }^{6}$ Yi Chen, ${ }^{1,2}$ \\ Guoping Li, ${ }^{1,2}$ Changyu Li, ${ }^{1,2}$ \\ Deliang Fu, ${ }^{5}$ Wanghong \\ $\mathrm{Xu},{ }^{3,4}$ Xiaolin Wang ${ }^{1,2}$ \\ 'Shanghai Institute of Medical Imaging, \\ ${ }^{2}$ Department of Interventional \\ Radiology, Zhongshan Hospital, \\ ${ }^{3}$ Department of Epidemiology, \\ School of Public Health, ${ }^{4}$ Key \\ Laboratory of Public Health Safety, \\ Ministry of Education, ${ }^{5}$ Department \\ of Pancreatic Surgery, Institute of \\ Pancreatic Disease, Huashan Hospital, \\ ${ }^{6}$ Department of Pancreatic Surgery, \\ Zhongshan Hospital, Fudan University, \\ Shanghai, People's Republic of China \\ *These authors contributed equally \\ to this work
}

\begin{abstract}
Pancreatic ductal adenocarcinoma (PDAC) is one of the most lethal malignancies with a 5-year survival rate of $<7 \%$. Carbohydrate antigen 19-9 (CA19-9) and carcinoembryonic antigen (CEA) are often used to predict the outcome of the malignancy independently. However, the joint prognostic effect of the two tumor biomarkers has not been well determined. The study assessed the joint role of preoperative CA19-9 and CEA in the prognostic prediction of resectable PDAC in a large cohort of patients. The study enrolled 460 eligible patients who were ready to undergo surgery for PDAC. Restricted cubic spline and direct-adjusted survival curve revealed the nonlinear association between the biomarker levels and prognosis of patients. Combination of preoperative CA19-9 and CEA effectively improved the prognostic prediction. About $100 \mathrm{U} / \mathrm{mL}$ of CA19-9 and $10 \mu \mathrm{g} / \mathrm{mL}$ of CEA were revealed as potential assistant index for prognostic prediction in patients with resectable PDAC and may be used as one of the criteria to assess the resectability of PDAC.
\end{abstract}

Keywords: pancreatic cancer, prognosis, tumor biomarkers, CA19-9, CEA

\section{Introduction}

Pancreatic ductal adenocarcinoma (PDAC) is one of the most lethal malignancies with a 5-year survival rate of $<7 \% .^{1,2} \mathrm{With}$ increasing incidence and mortality, PDAC is estimated to cause the fourth highest cancer-related deaths in the People's Republic of China in the next few years. Radical resection is the only potential curative therapy for PDAC and has achieved $\sim 20 \%$ of 5-year survival rate during the past few decades. ${ }^{3-5}$ However, some patients with extremely low 5-year postoperative survival rate ${ }^{5,6}$ benefit little from the surgical therapy, which is possibly due to the undetectable invasion or metastases and may lead to recurrence and impaired prognosis. ${ }^{7}$ It has important clinical significance in identifying these individuals from all potentially resectable patients.

Multiple studies have confirmed that serum carbohydrate antigen 19-9 (CA19-9) and carcinoembryonic antigen (CEA) are related with tumor burden of PDAC due to their close association with cancer cell adhesion, metabolism, and proliferation..$^{5,8,9}$ In clinical practice, CA19-9 or CEA is often used to predict the outcomes of patients with resectable PDAC. ${ }^{10}$ Ferrone et $\mathrm{al}^{11}$ reported that preoperative CA19-9 > $200 \mathrm{U} / \mathrm{mL}$ acts as a strong predictor of worse overall survival (OS) in Western patients with resectable PDAC. Ni et $\mathrm{al}^{10}$ reported that CEA $>5 \mu \mathrm{g} / \mathrm{mL}$ and CA19-9 $>1,000 \mathrm{U} / \mathrm{mL}$ can be used as indicators of poor prognosis in Chinese patients with resectable PDAC. 
It is reported that CA19-9 and CEA have potential application value in clinic by identifying individuals with poor survival even after pancreatectomy, and thus optimizing clinical management. ${ }^{12}$ Recently, Liu et $\mathrm{al}^{6}$ reported that patients with preoperative CEA (+)/CA125 (+)/CA19-9 $\geq 1,000 \mathrm{U} / \mathrm{mL}$ benefited very little from the surgical resection therapy, which greatly improved clinical management and therapeutic selection for patients with localized pancreatic cancer. However, joint prognostic effect of the biomarkers was often neglected in previous studies, and the cutoff point value of the biomarkers was not uniform because of the relatively small sample sizes. ${ }^{4,5,10-13}$

Herein, we evaluate the joint effect of preoperative CEA and CA19-9 levels in the outcome prediction in a large cohort of patients. Furthermore, restricted cubic spline and direct-adjusted survival curve were used to investigate how best to use these biomarkers to distinguish those patients who would benefit least from the surgical therapy.

\section{Patients and methods}

\section{Patients and data collection}

Five hundred twelve patients undergoing surgery for PDAC from two clinical centers (Zhongshan Hospital and Huashan Hospital, Fudan University, People's Republic of China) from April 2012 to January 2015 were recruited in the study. Assessment of resectability was mainly based on the National Comprehensive Cancer Network (NCCN) guidelines before surgery. ${ }^{14,15}$ Patients who underwent Whipple or distal pancreatectomy were included in this study. Patients receiving previous chemotherapy or patients about to die due to postoperative complications within 14 days were not included in the study. Patients provided written informed consent, and all the clinical procedures were approved by the Institutional Review Committee of Zhongshan Hospital, Fudan University (IRB approval number: B2014-098).

Demographic and clinical characteristics of the patients, such as age, gender, preoperative serum levels of CA19-9 and CEA, presence of diabetes, tumor location, chemotherapy (received gemcitabine or fluorouracil-based chemotherapy or not), and Classification of Malignant Tumours (TNM) stage, were extracted from the electronic medical records. Serum levels of CA19-9 and CEA were examined at the clinical laboratory for each patient within 1 week before surgery. Upper detectable limit of CA19-9 value was 10,000 U/mL. The patients were categorized into subgroups according to CA19-9 ( $<37,37$ to $<100,100$ to $<200,200$ to $<400$, 400 to $<800$, and $\geq 800 \mathrm{U} / \mathrm{mL}$ ) and CEA levels ( 0.0 to $<3.0$, 3.0 to $<5.0,5.0$ to $<10.0$, and $\geq 10.0 \mu \mathrm{g} / \mathrm{mL}$ ). TNM stage was determined based on the preoperative imaging examination (computed tomography/magnetic resonance imaging) and postoperative pathologic review according to the American Joint Committee on Cancer (AJCC) criteria. ${ }^{16}$

\section{Follow-up}

Follow-up survey was conducted for all patients through telephone call by a full-time investigator. Telephone call survey followed a standardized protocol and was carried out every 3 months. Vital status and death date for the patients were obtained up to June 2015. Survival time was calculated from the date of surgery until the date of death, or the date of last call on June 30, 2015, whichever occurred first. A total of $460(90 \%)$ patients responded to the telephonic follow-up.

\section{Statistical analysis}

All data were key-entered and double-checked using Epidata 3.1 for Windows by two independent investigators. Wilcoxon rank test (continuous variables) and chi-square test (categorical variables) were used to compare clinical characteristics across the subgroups. Log-rank test was used to compare the survival between different subgroups. The direct-adjusted survival curve was based on a stratified Cox regression model proposed by Zhang et al. ${ }^{17,18}$ Median survival time and 3- and 5-year survival rates were calculated using the direct-adjusted survival Statistical Analysis System (SAS) macro. Cox model with restricted cubic spline functions was used to illustrate the nonlinear relationship of CA19-9 and CEA with OS of PDAC. Joint effect of preoperative CA19-9 and CEA was evaluated by the Cox model and was presented using hazard ratio. Missing data were excluded from analysis. All tests were two sided, and $P$-values $<0.05$ were considered statistically significant. All statistical analyses were conducted using SAS 9.2.

\section{Results}

A total of 460 patients reposed to the telephone call follow-up. Fifty-two nonresponders showed no significant differences in the baseline characteristics with the responders. Of the responded patients, $276(60 \%)$ were recruited from Zhongshan Hospital and 184 (40\%) from Huashan Hospital. No significant hospital and gender differences were observed in the baseline clinical characteristics and OS.

Preoperative CA19-9 and CEA values were increased with advanced AJCC stage (Figure 1). Baseline characteristics of all included patients are listed in Table 1. Median preoperative CA19-9 and CEA values were 101.9 U/mL (q1-q3: 27.4-439.7 U/mL) and $2.8 \mu \mathrm{g} / \mathrm{mL}(\mathrm{q} 1-\mathrm{q} 3: 1.7-5.1 \mu \mathrm{g} / \mathrm{mL})$, respectively. As presented in Table 1, patients with higher 

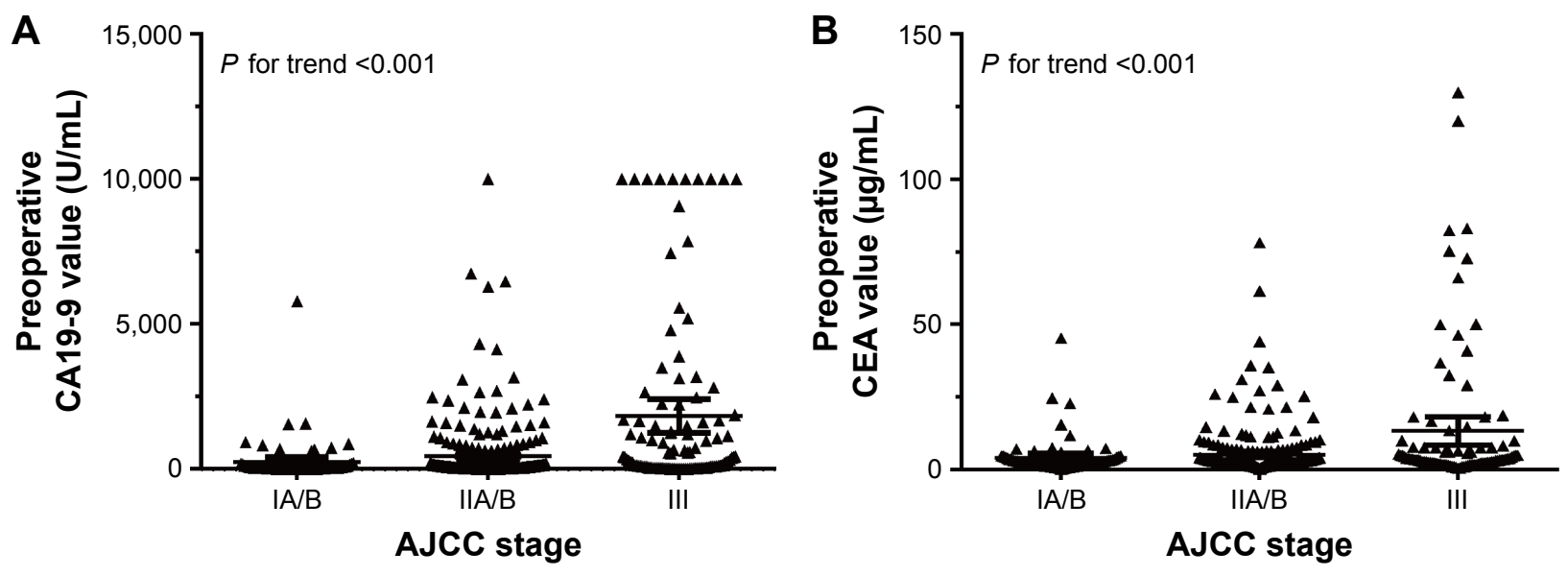

Figure I Preoperative CAI9-9 level and CEA level increased with advanced AJCC stage.

Notes: The grouped scatter plot showed that the preoperative CAI9-9 (A) and CEA (B) values were increased with advanced AJCC stage $(P$ for trend $<0.001$ and 0.01 , respectively)

Abbreviations: AJCC, American Joint Committee on Cancer; CA19-9, carbohydrate antigen 19-9; CEA, carcinoembryonic antigen.

CA19-9 level ( $\geq 37 \mathrm{U} / \mathrm{mL})$ or higher CEA level ( $\geq 5 \mu \mathrm{g} / \mathrm{mL})$ were older and more likely to have lymph metastases, advanced tumor stages, and later stages were according to the AJCC. Gemcitabine-based chemotherapy was a conventional postoperative adjuvant therapy for patients with lymph node metastases, significant consistency was found between postoperative chemotherapy and lymph node metastases $(P<0.0001)$.

Median survival time for all 460 resectable patients was 24.0 (95\% confidence interval [CI]: 18.0, 28.0) months. The survival time was significantly longer in patients with CA19-9 $<37 \mathrm{U} / \mathrm{mL}$ than those with CA19-9 $\geq 37 \mathrm{U} / \mathrm{mL}$ (median: 37.0 vs 18.0 months, log-rank $P<0.001$ ). Figure $2 \mathrm{~A}$ and $\mathrm{B}$ shows the nonlinear association of preoperative CA19-9 and CEA level with cancer survival. Generally, the risk of cancer death was observed to increase with increasing levels of preoperative CA19-9 and CEA. However, the risk was increased sharply when CA19-9 was $<100 \mathrm{U} / \mathrm{mL}$ or CEA was $<10 \mu \mathrm{g} / \mathrm{mL}$, but became slow and steady thereafter. The Kaplan-Meier survival curve using the above-referenced cut point is presented in Figure 3.

Table I Demographic and baseline clinical characteristics of patients with resectable pancreatic adenocarcinoma $(n=460)$

\begin{tabular}{|c|c|c|c|c|c|c|c|}
\hline \multirow[t]{2}{*}{ Characteristics } & \multirow{2}{*}{$\begin{array}{l}\text { All patients } \\
(n=460)\end{array}$} & \multicolumn{3}{|c|}{ Preoperative serum CAI9-9a } & \multicolumn{3}{|c|}{ Preoperative serum CEA ${ }^{\mathrm{b}}$} \\
\hline & & $\begin{array}{l}<37 \mathrm{U} / \mathrm{mL} \\
(\mathrm{n}=153)\end{array}$ & $\begin{array}{l}\geq 37 \mathrm{U} / \mathrm{mL} \\
(\mathrm{n}=301)\end{array}$ & $P$-value & $\begin{array}{l}<5 \mu \mathrm{g} / \mathrm{mL} \\
(\mathrm{n}=304)\end{array}$ & $\begin{array}{l}\geq 5 \mu \mathrm{g} / \mathrm{mL} \\
(\mathrm{n}=104)\end{array}$ & $P$-value \\
\hline Age, median ( $q \mathrm{I}-\mathrm{q} 3$, years) & $62(56-68)$ & $60(54-66)$ & $62(57-69)$ & $0.0045^{*}$ & $61(56-67)$ & $65(57-72)$ & $0.0 I^{*}$ \\
\hline Diabetes, N (\%) & & & & 0.23 & & & 0.58 \\
\hline Yes & $102(24.2)$ & $29(20.7)$ & $72(26.0)$ & & $70(23.3)$ & $27(26.0)$ & \\
\hline No & $322(75.8)$ & III (79.3) & $205(74.0)$ & & $232(76.7)$ & $77(74.0)$ & \\
\hline Tumor location, N (\%) & & & & 0.13 & & & 0.39 \\
\hline Head of pancreas & $143(3||)$. & $54(35.5)$ & $86(28.6)$ & & 97 (31.9) & $38(36.5)$ & \\
\hline Body or tail of pancreas & $317(68.9)$ & $98(64.5)$ & $215(7 \mid .4)$ & & $207(68.1)$ & $66(63.5)$ & \\
\hline Tumor stage, $N(\%)$ & & & & $<0.0001 *$ & & & 0.05 \\
\hline $\mathrm{TI} / \mathrm{T} 2$ & II 15 (25.9) & $56(38.9)$ & $58(19.9)$ & & $83(28.3)$ & $18(18.4)$ & \\
\hline $\mathrm{T} 3 / \mathrm{T} 4$ & $328(74.1)$ & $88(6 \mathrm{I} .1)$ & $234(80.1)$ & & $210(71.7)$ & $80(81.6)$ & \\
\hline Lymph node stage, N (\%) & & & & 0.08 & & & $0.04 *$ \\
\hline $\mathrm{NI}$ & $206(55.2)$ & $59(38.8)$ & $143(47.5)$ & & $120(39.5)$ & $53(5 \mathrm{I} .0)$ & \\
\hline No & $254(44.8)$ & $93(6 \mid .2)$ & $158(52.5)$ & & $184(60.5)$ & $51(49.0)$ & \\
\hline AJCC stage, $N(\%)$ & & & & $<0.0001 *$ & & & $0.03 *$ \\
\hline $\mathrm{IA} / \mathrm{IB}$ & $68(15.4)$ & $38(26.4)$ & $30(10.3)$ & & $54(I 8.4)$ & $9(9.2)$ & \\
\hline$\| \mathrm{A} / I \mathrm{~B}$ & $286(64.6)$ & $89(6 \mid .8)$ & $190(65.1)$ & & $186(63.5)$ & $62(63.3)$ & \\
\hline III & $89(22.1)$ & $17(11.8)$ & $72(24.7)$ & & $53(18.1)$ & $27(27.5)$ & \\
\hline Chemotherapy, N (\%) & $360(78.3)$ & $119(78.3)$ & $234(77.7)$ & 0.89 & $226(74.34)$ & $84(80.1)$ & 0.19 \\
\hline
\end{tabular}

Notes: aSeven missing values, ${ }^{\circ} 52$ missing values. *Statiscally significant.

Abbreviations: AJCC, American Joint Committee on Cancer; CA19-9, carbohydrate antigen 19-9; CEA, carcinoembryonic antigen. 

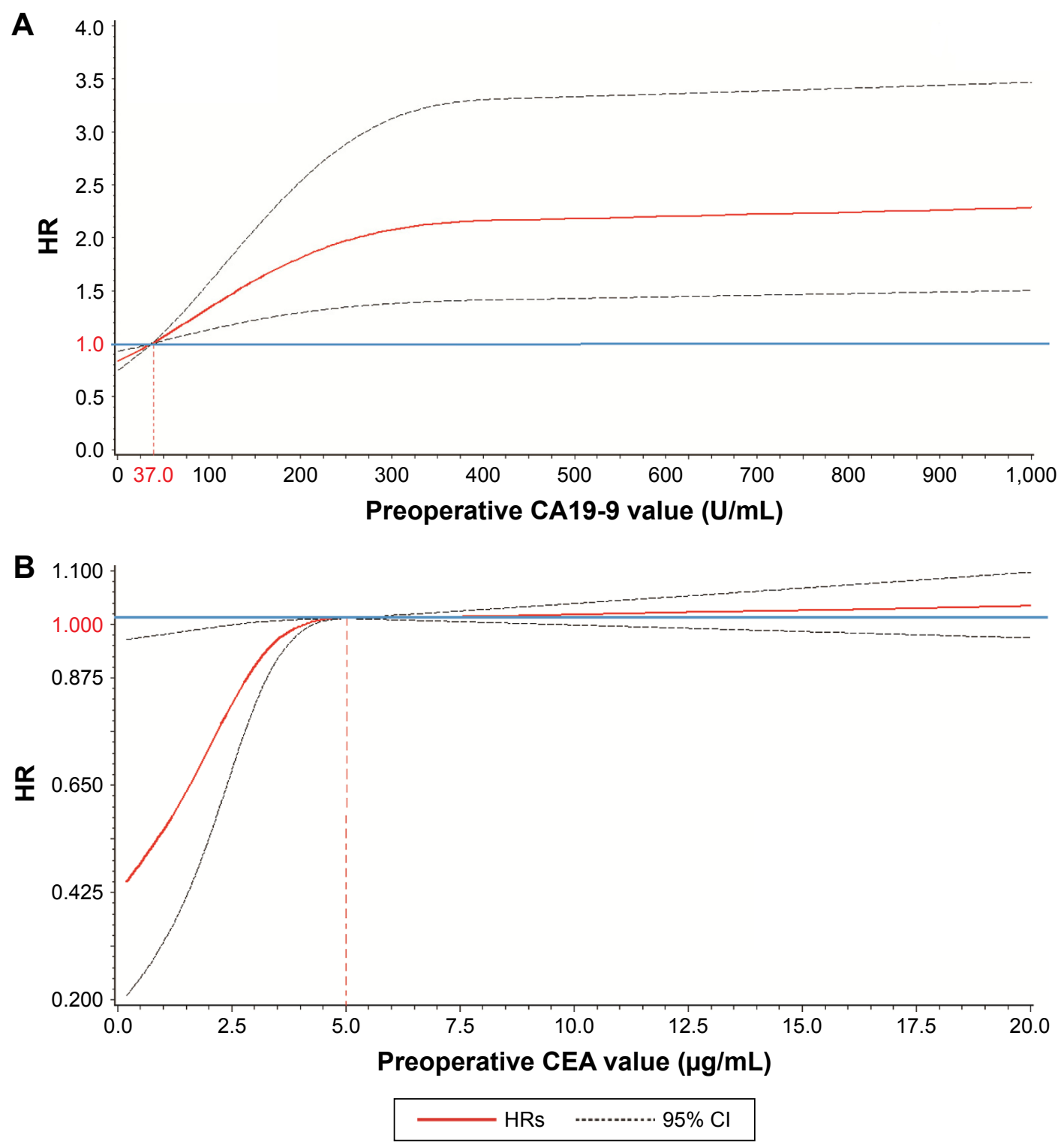

Figure 2 Nonlinear relationship of CAI9-9 and CEA with the risk of death in resectable pancreatic ductal adenocarcinoma patients.

Notes: The blue line represents the reference HR $=1.0$ and the dotted line presented the $95 \% \mathrm{Cl}$ of the HR. The risk of cancer death was observed to increase with increasing levels of preoperative CAI9-9 (A) and CEA (B). However, the risk was increased sharply when CAI9-9 < I00 U/mL or CEA $<10 \mu \mathrm{g} / \mathrm{mL}$, but became slow and steady thereafter.

Abbreviations: CA19-9, carbohydrate antigen 19-9; CEA, carcinoembryonic antigen; Cl, confidence interval; HR, hazard ratio.

The optimal cutoff points of preoperative CA19-9 and CEA levels were predicted to observe the outcomes of PDAC resectable patients. As shown in Table 2 and Figure 4A and B, after adjusting age, gender, tumor stage, lymph node status, and tumor location, the subgroups with preoperative CA19-9 $<100 \mathrm{U} / \mathrm{mL}$ or CEA $<10 \mu \mathrm{g} / \mathrm{mL}$ had much longer adjusted median survival time and higher 3- and 5-year survival rates than those compared with CA19-9 $\geq 100 \mathrm{U} / \mathrm{mL}$ or CEA $\geq 10 \mu \mathrm{g} / \mathrm{mL}$. Log-rank test of binary discretized levels confirmed that $100 \mathrm{U} / \mathrm{mL}$ of CA19-9 and $10 \mu \mathrm{g} / \mathrm{mL}$ of CEA were the best cutoff points to predict
PDAC prognosis $(P<0.0001)$. Log-rank test further confirmed that patients with preoperative CA19-9 $<100 \mathrm{U} / \mathrm{mL}$ had significant OS than patients with CA19-9 $\geq 100 \mathrm{U} / \mathrm{mL}$ $(P<0.0001)$, whereas in patients with preoperative CA19$9 \geq 100 \mathrm{U} / \mathrm{mL}$, serum CEA $\geq 10 \mu \mathrm{g} / \mathrm{mL}$ was a strong predictor for shorter OS $(P=0.0482)$.

Table 3 presents independent and joint effect of CA19-9 and CEA levels on OS in PDAC patients. The subgroup of patients with CA19-9 $\geq 100 \mathrm{U} / \mathrm{mL}$ had 2.9-fold risk $(95 \%$ CI: 2.0-4.3) of death when compared with those patients having CA19-9 $<100 \mathrm{U} / \mathrm{mL}$ and had 5.5-fold risk (95\% CI: 

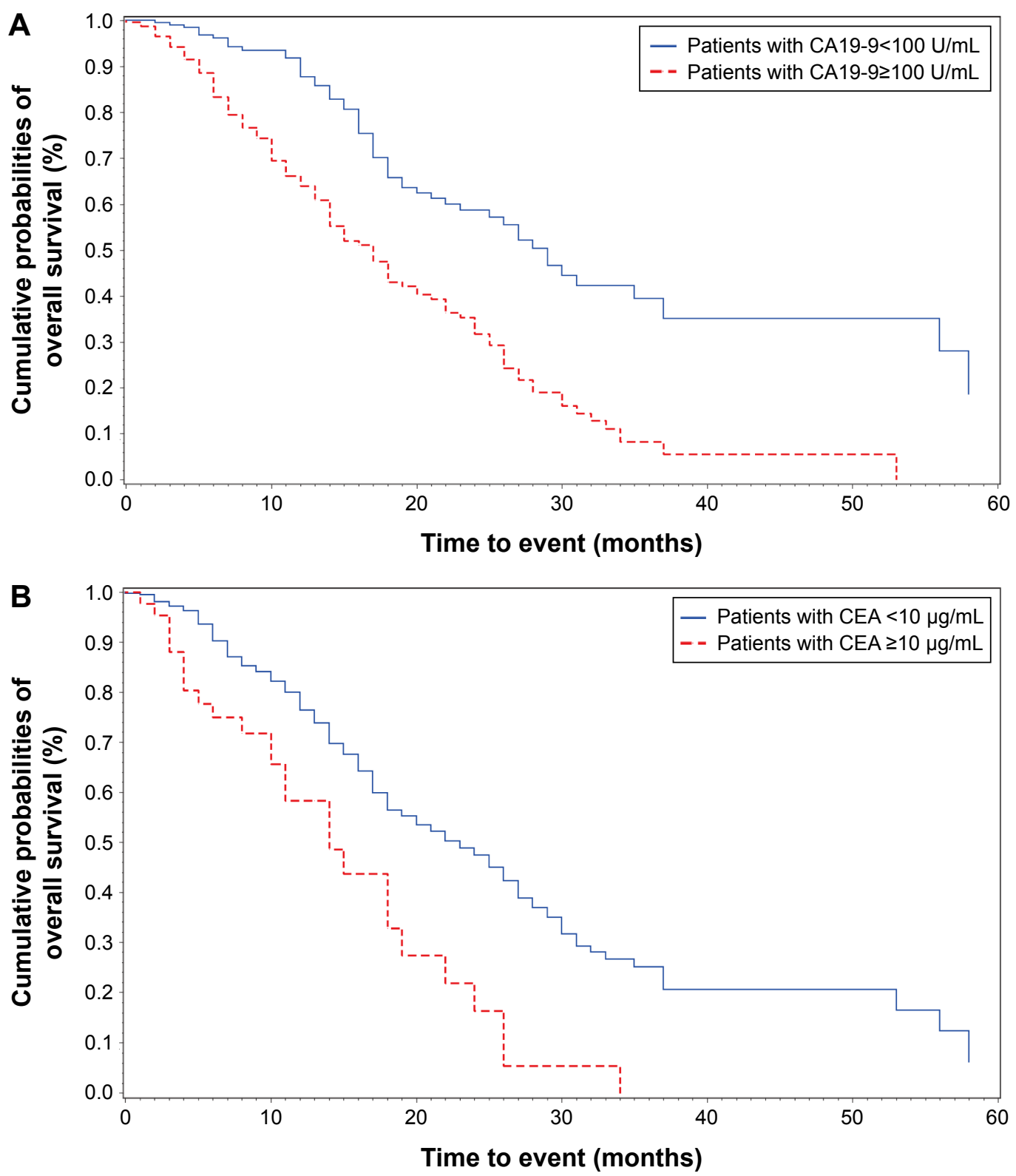

Figure 3 Preoperative CAI9-9 and CEA levels were strong independent prognostic indicators for resectable pancreatic ductal adenocarcinoma.

Notes: The Kaplan-Meier survival curve showed that (A) patients with preoperative CAI9-9 value of $\geq 100$ benefit little from the surgery. (B) Patients with preoperative CEA value of $\geq 10$ benefit little from the surgery.

Abbreviations: CAI9-9, carbohydrate antigen 19-9; CEA, carcinoembryonic antigen.

3.1-9.7) when having $\mathrm{CEA} \geq 10 \mu \mathrm{g} / \mathrm{mL}$ simultaneously. The risk of death increased sharply with CEA level until it reaches $3.0 \mu \mathrm{g} / \mathrm{mL}$ in both the patient groups with CA19-9 $\geq 100 \mathrm{U} / \mathrm{mL}$ and CA19-9 $<100 \mathrm{U} / \mathrm{mL}$ (Figure 5).

\section{Discussion}

In this follow-up survey of patients with resectable PDAC, we noticed that the patients with preoperative CA19-9 $<100 \mathrm{U} / \mathrm{mL}$ or $\mathrm{CEA}<10 \mu \mathrm{g} / \mathrm{mL}$ had much longer adjusted median survival time and higher 5-year survival rates than those with CA19-9 $\geq 100 \mathrm{U} / \mathrm{mL}$ or CEA $\geq 10 \mu \mathrm{g} / \mathrm{mL}$.
By contrast of the $19 \%$ of 5-year survival rate in patients with CA19-9 $<100 \mathrm{U} / \mathrm{mL}$, the 5 -year survival rate was only $3 \%$ in patients with CA19-9 $\geq 100 \mathrm{U} / \mathrm{mL}$ and as low as $0.5 \%$ in patients who had $C E A \geq 10 \mu \mathrm{g} / \mathrm{mL}$, respectively. Our results suggest that CA19-9 $<100 \mathrm{U} / \mathrm{mL}$ can be used not only as a predictor of the outcome of PDAC patients but also as a criterion to determine resectability of localized PDAC.

In this study, increased preoperative serum levels of CA19-9 and CEA were observed to predict poor prognosis in patients with resectable PDAC. Our results are consistent with most previous studies, ${ }^{5,10,11,13}$ and can be explained by 
Table 2 Adjusted overall survival according to the preoperative serum levels of CA19-9 and CEA

\begin{tabular}{|c|c|c|c|c|}
\hline $\begin{array}{l}\text { Serum } \\
\text { levels }\end{array}$ & $\begin{array}{l}\text { No. of } \\
\text { patients }\end{array}$ & $\begin{array}{l}\text { Median } \\
\text { survival time } \\
\text { (months) }\end{array}$ & $\begin{array}{l}\text { 3-year } \\
\text { survival rate }\end{array}$ & $\begin{array}{l}\text { 5-year } \\
\text { survival rate }\end{array}$ \\
\hline \multicolumn{5}{|c|}{ CAI9-9 (U/mL) } \\
\hline$<37$ & 153 & 34 & 0.42 & 0.19 \\
\hline $37-<100$ & 72 & 34 & 0.44 & 0.20 \\
\hline $100-<200$ & 51 & 15 & 0.10 & 0.02 \\
\hline $200-<400$ & 54 & 18 & 0.19 & 0.05 \\
\hline $400-<800$ & 45 & 22 & 0.23 & 0.07 \\
\hline$\geq 800$ & 82 & 14 & 0.11 & 0.02 \\
\hline \multicolumn{5}{|c|}{ CEA $(\mu g / m L)^{b}$} \\
\hline $0.0-<3.0$ & 219 & 26 & 0.31 & 0.14 \\
\hline $3.0-<5.0$ & 86 & 24 & 0.26 & 0.10 \\
\hline $5.0-<10.0$ & 62 & 28 & 0.37 & 0.17 \\
\hline$\geq 10.0$ & 43 & 16 & 0.16 & 0.04 \\
\hline
\end{tabular}

Notes: Adjusted for age (as continuous variable), gender, tumor stage, lymph node

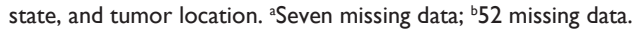

Abbreviations: CAI9-9, carbohydrate antigen 19-9; CEA, carcinoembryonic antigen. the close associations of CA19-9 and CEA with cancer cell proliferation and metastases. ${ }^{8}, 19$ However, neither serum CA19-9 nor CEA can be used alone as a predictor of prognosis because patients with negative Lewis antigen $\left(\mathrm{Le}^{\mathrm{a}-\mathrm{b}-}\right)$ will not produce CA19-9, ${ }^{20,21}$ and CEA is not a specific biomarker for pancreatic cancer..$^{22}$ Therefore, CA19-9 and CEA are usually used as subsidiary indexes to predict the prognosis of PDAC in patients.

More importantly, we found that $100 \mathrm{U} / \mathrm{mL}$ of CA19-9 and $10 \mu \mathrm{g} / \mathrm{mL}$ of CEA can be used as the optimal cutoff values in predicting the survival time and survival rates in the potential resectable PDAC patients. Combined use of the two biomarkers can predict prognosis of the patients very well, which is consistent with a previous study, ${ }^{23}$ in which Reitz et al found that the combination of CEA and CA19-9 was significantly better than CEA or CA19-9 alone in the prognostic prediction
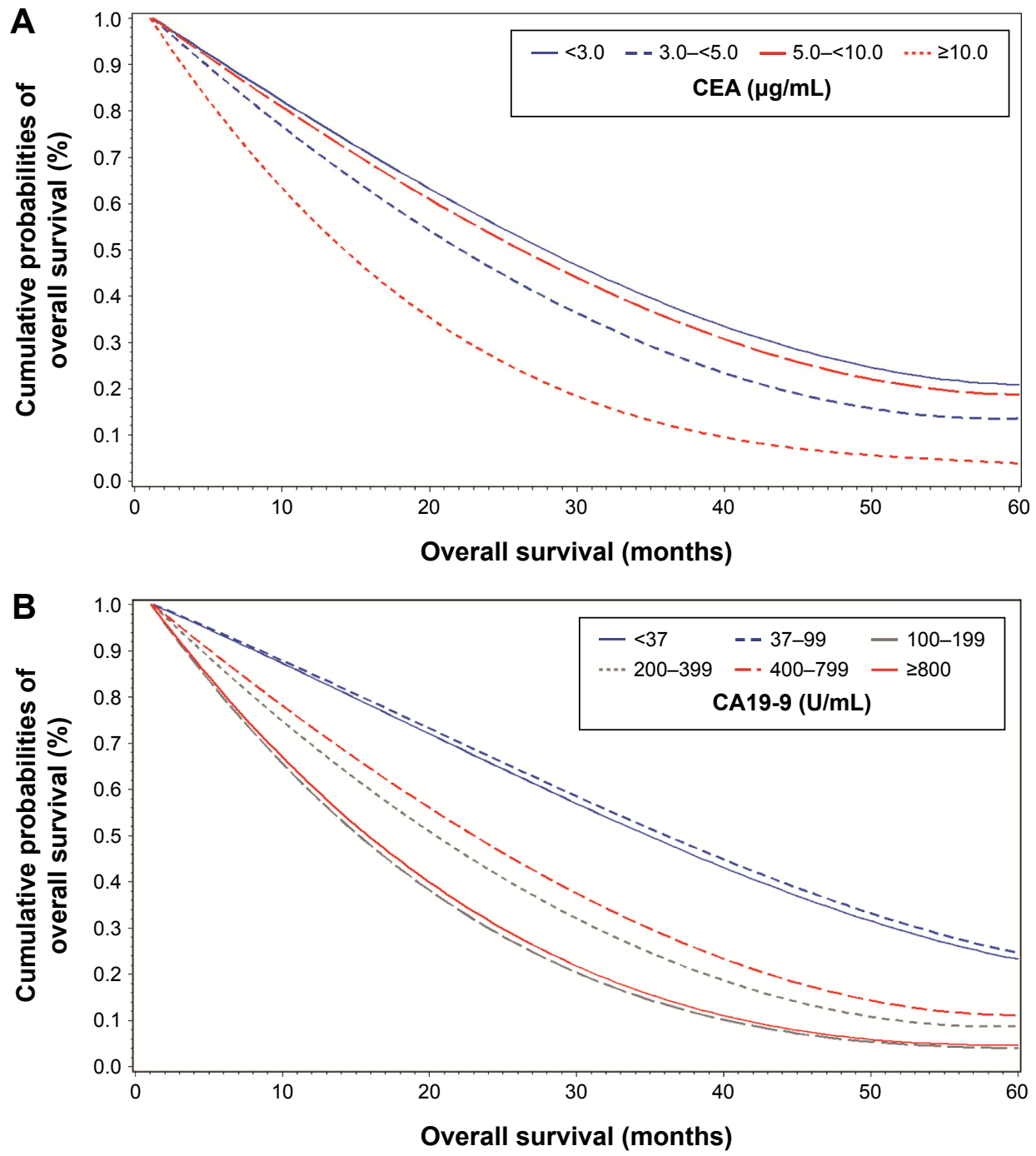

Figure 4 Adjusted survival curve of resectable pancreatic ductal adenocarcinoma patients by CA 19-9 and CEA levels.

Notes: The adjusted Kaplan-Meier survival curve showed that patients benefit little from the surgery with increasing level of CAI9-9 (A) and CEA (B). Age, gender, and tumor stage were all adjusted in the survival curve.

Abbreviations: CA19-9, carbohydrate antigen 19-9; CEA, carcinoembryonic antigen. 
Table 3 HRs of CAI9-9 and CEA with overall survival of resectable pancreatic adenocarcinoma

\begin{tabular}{|c|c|c|c|c|}
\hline $\begin{array}{l}\text { Serum } \\
\text { levels }\end{array}$ & $\begin{array}{l}\text { No. of } \\
\text { patients }\end{array}$ & $\begin{array}{l}\text { Median survival } \\
\text { time (months) }\end{array}$ & $\begin{array}{l}5 \text {-year } \\
\text { survival rate }\end{array}$ & $\begin{array}{l}\text { HR } \\
(95 \% \mathrm{Cl})\end{array}$ \\
\hline \multicolumn{5}{|c|}{ CAI9-9 (U/mL) } \\
\hline$<100.0$ & 225 & 35 & 0.19 & 1.0 \\
\hline$\geq 100.0$ & 232 & 17 & 0.03 & $2.9(2.0,4.3)$ \\
\hline $\mathrm{CEA}<10$ & 168 & 18 & 0.03 & $2.7(1.8,4.0)$ \\
\hline$C E A \geq 10$ & 39 & II & 0.005 & $5.5(3.1,9.7)$ \\
\hline
\end{tabular}

Notes: HR: adjusted for age (as continuous variable), gender, tumor stage, lymph node state, and tumor location.

Abbreviations: CA19-9, carbohydrate antigen 19-9; CEA, carcinoembryonic antigen; $\mathrm{Cl}$, confidence interval; $\mathrm{HR}$, hazard ratio.

of pancreatic cancer. In this study, patients with preoperative CA19-9 $\geq 100 \mathrm{U} / \mathrm{mL}$ and CEA $\geq 10 \mu \mathrm{g} / \mathrm{mL}$ benefitted little from the surgery, with only 11 months of median survival time, which is not much better than 9 months of survival time in advanced patients receiving nab-paclitaxel plus gemcitabine chemotherapy. ${ }^{24,25}$ It seems that these patients should have been considered as unresectable and should receive conservative treatment. However, rigorous clinical trial designs were needed to validate the hypothesis.

Currently, assessment of resectability was mainly based on the radiographic examination and anatomical analysis according to the NCCN guidelines. ${ }^{15,26}$ These methods cannot detect the invasion or subclinical metastases, which may result in the early recurrence and impaired prognosis. ${ }^{7,27}$ For the patients who are factually not amenable to resection, surgical therapy is not necessary and even harmful because of the possible postsurgical complications. ${ }^{13,28}$ It has been suggested that systematic chemotherapy was superior over unnecessary surgical therapies for these patients. Our results suggest that CA19-9 $<100 \mathrm{U} / \mathrm{mL}$ and/or CEA $<10 \mu \mathrm{g} / \mathrm{mL}$ may be used as one of the criteria to determine the resectability of localized PDAC.

Strengths of this study include large sample size, high response rate to follow-up, and advanced statistical methods, which show the potential superiority in the survival analysis. Several limitations of the study include, first, chance could not be excluded for the small number of patients with CA19-9 $\geq 100 \mathrm{U} / \mathrm{mL}$ and CEA $\geq 10 \mu \mathrm{g} / \mathrm{mL}$. Studies with larger sample size are needed to confirm our results. Second, the results were limited to a single ethnic background and the results should be generalized to other ethnic groups. Third, potential selection bias should not be omitted in this study. As mentioned earlier, the assessment of resectability was mainly according to the radiographic examination. The assessment of resection, especially the assessment of extended resection, was controversial and subjective. ${ }^{13}$ Clinical experience of a surgeon at times greatly affects on the judgment. Furthermore, randomized studies are still needed to address these limitations. At last, the effect of preoperative CA19-9 and CEA values was mainly investigated in this study, more clinical characteristics should be considered in application.

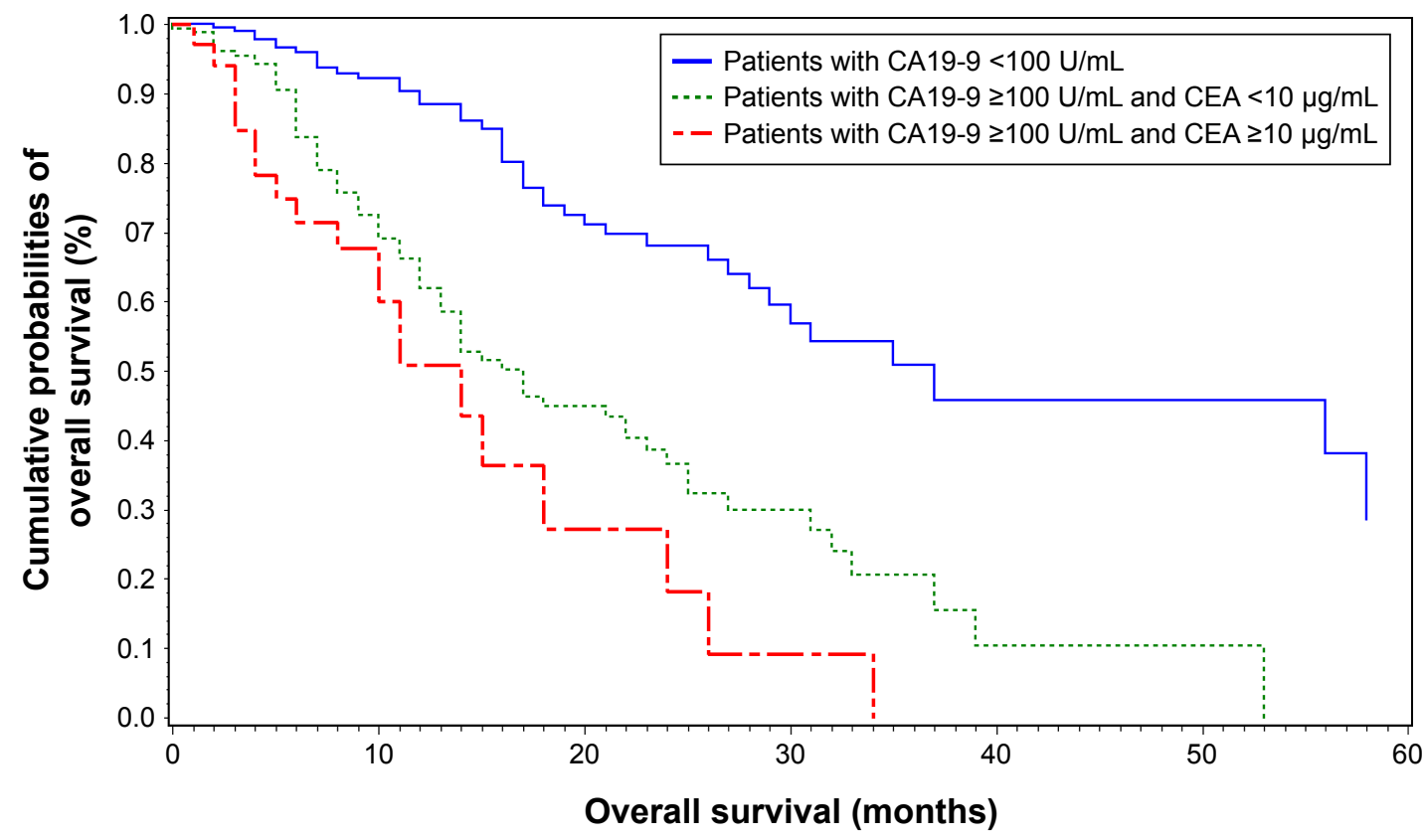

Figure 5 Kaplan-Meier survival curves of patients with preoperative CAI9-9.

Notes: The blue line indicates that patients with preoperative CAI9-9 value $<100 \mathrm{U} / \mathrm{mL}$ benefit most from surgery. Patients with both CAI9-9 $>100 \mathrm{U} / \mathrm{mL}$ and $\mathrm{CEA} \geq 10 \mu \mathrm{g} / \mathrm{mL}$ had the worst prognosis.

Abbreviations: CAI9-9, carbohydrate antigen 19-9; CEA, carcinoembryonic antigen. 


\section{Conclusion}

In conclusion, the joint of $100 \mathrm{U} / \mathrm{mL}$ of preoperative serum of CA19-9 and $10 \mu \mathrm{g} / \mathrm{mL}$ of CEA may act as optimal cutoff points to predict the outcomes of resectable PDAC and may be used as one of the criteria to assess the resectability of PDAC.

\section{Acknowledgments}

This work was supported by the Rong-Chang Charity Fund of Shanghai Charity Foundation and Zhongshan Hospital Fund for Young Scholars (2015ZSQN31). We are grateful for all staff and subjects participating in the study.

\section{Disclosure}

The authors report no conflicts of interest in this work.

\section{References}

1. Siegel R, Ma J, Zou Z, Jemal A. Cancer statistics, 2014. CA Cancer J Clin. 2014;64(1):9-29.

2. Ryan DP, Hong TS, Bardeesy N. Pancreatic adenocarcinoma. $N$ Engl J Med. 2014;371(11):1039-1049.

3. Serrano PE, Cleary SP, Dhani N, et al. Improved long-term outcomes after resection of pancreatic adenocarcinoma: a comparison between two time periods. Ann Surg Oncol. 2014;22(4):1160-1167.

4. Sohn TA, Yeo CJ, Cameron JL, et al. Resected adenocarcinoma of the pancreas-616 patients: results, outcomes, and prognostic indicators. J Gastrointest Surg. 2000;4(6):567-579.

5. Humphris J, Chang D, Johns A, et al. The prognostic and predictive value of serum CA19. 9 in pancreatic cancer. Ann Oncol. 2012;23(7): 1713-1722.

6. Liu L, Xu H, Wang W, et al. A preoperative serum signature of CEA+/ CA125+/CA19-9 $\geq 1000 \mathrm{U} / \mathrm{mL}$ indicates poor outcome to pancreatectomy for pancreatic cancer. Int J Cancer. 2015;136(9):2216-2227.

7. Levy MJ, Topazian M, Keeney G, et al. Preoperative diagnosis of extrapancreatic neural invasion in pancreatic cancer. Clin Gastroenterol Hepatol. 2006;4(12):1479-1482.

8. Koprowski H, Herlyn M, Steplewski Z, Sears HF. Specific antigen in serum of patients with colon carcinoma. Science. 1981;212(4490): $53-55$.

9. Goonetilleke K, Siriwardena A. Systematic review of carbohydrate antigen (CA 19-9) as a biochemical marker in the diagnosis of pancreatic cancer. Eur J Surg Oncol. 2007;33(3):266-270.

10. Ni X, Bai X, Mao Y, et al. The clinical value of serum CEA, CA19-9, and CA242 in the diagnosis and prognosis of pancreatic cancer. Eur $J$ Surg Oncol. 2005;31(2):164-169.

11. Ferrone CR, Finkelstein DM, Thayer SP, Muzikansky A, Fernandez-del Castillo C, Warshaw AL. Perioperative CA19-9 levels can predict stage and survival in patients with resectable pancreatic adenocarcinoma. J Clin Oncol. 2006;24(18):2897-2902.

OncoTargets and Therapy

\section{Publish your work in this journal}

OncoTargets and Therapy is an international, peer-reviewed, open access journal focusing on the pathological basis of all cancers, potential targets for therapy and treatment protocols employed to improve the management of cancer patients. The journal also focuses on the impact of management programs and new therapeutic agents and protocols on
12. Kim YC, Kim HJ, Park JH, et al. Can preoperative CA19-9 and CEA levels predict the resectability of patients with pancreatic adenocarcinoma? J Gastroenterol Hepatol. 2009;24(12):1869-1875.

13. Yang X, Hao J, Zhu CH, et al. Survival benefits of Western and traditional Chinese medicine treatment for patients with pancreatic cancer. Medicine. 2015;94(26):e1008.

14. Tempero MA, Arnoletti JP, Behrman SW, et al. Pancreatic adenocarcinoma, version 2.2012: featured updates to the NCCN Guidelines. J Natl Compr Canc Netw. 2012;10(6):703-713.

15. Tempero MA, Arnoletti JP, Behrman SW, et al. Pancreatic adenocarcinoma, Version 2.2012 featured updates to the NCCN Guidelines. J Natl Compr Canc Netw. 2012;10(6):703-713.

16. Sobin LH, Gospodarowicz MK, Wittekind C. TNM Classification of Malignant Tumours. Malden, MA: John Wiley \& Sons; 2011.

17. Zhang X, Loberiza FR, Klein JP, Zhang MJ. A SAS macro for estimation of direct adjusted survival curves based on a stratified Cox regression model. Comput Methods Programs Biomed. 2007;88(2):95-101.

18. Klein JP, Moeschberger ML. Survival Analysis: Techniques for Censored and Truncated Data. Dordrecht: Springer Science \& Business Media; 2003.

19. Benchimol S, Fuks A, Jothy S, Beauchemin N, Shirota K, Stanners CP. Carcinoembryonic antigen, a human tumor marker, functions as an intercellular adhesion molecule. Cell. 1989;57(2):327-334.

20. Tempero MA, Uchida E, Takasaki H, Burnett DA, Steplewski Z, Pour PM. Relationship of carbohydrate antigen 19-9 and Lewis antigens in pancreatic cancer. Cancer Res. 1987;47(20):5501-5503.

21. $\mathrm{He} \mathrm{M}, \mathrm{Wu} \mathrm{C}, \mathrm{Xu} \mathrm{J}$, et al. A genome wide association study of genetic loci that influence tumour biomarkers cancer antigen 19-9, carcinoembryonic antigen and $\alpha$ fetoprotein and their associations with cancer risk. Gut. 2014;63(1):143-151.

22. Moore T, Kupchik H, Marcon N, Zamcheck N. Carcinoembryonic antigen assay in cancer of the colon and pancreas and other digestive tract disorders. Am J Dig Dis. 1971;16(1):1-7.

23. Reitz D, Gerger A, Seidel J, et al. Combination of tumour markers CEA and CA19-9 improves the prognostic prediction in patients with pancreatic cancer. J Clin Pathol. 2015;68(6):427-433.

24. Von Hoff DD, Ervin T, Arena FP, et al. Increased survival in pancreatic cancer with nab-paclitaxel plus gemcitabine. $N$ Engl J Med. 2013; 369(18):1691-1703.

25. Goldstein D, El-Maraghi RH, Hammel P, et al. Nab-paclitaxel plus gemcitabine for metastatic pancreatic cancer: long-term survival from a phase III trial. J Natl Cancer Inst. 2015;107(2):dju413.

26. Soriano A, Castells A, Ayuso C, et al. Preoperative staging and tumor resectability assessment of pancreatic cancer: prospective study comparing endoscopic ultrasonography, helical computed tomography, magnetic resonance imaging, and angiography. Am J Gastroenterol. 2004; 99(3):492-501.

27. Ballehaninna UK, Chamberlain RS. The clinical utility of serum CA 19-9 in the diagnosis, prognosis and management of pancreatic adenocarcinoma: an evidence based appraisal. J Gastrointest Oncol. 2012; 3(2):105-119.

28. Billings BJ, Christein JD, Harmsen WS, et al. Quality-of-life after total pancreatectomy: is it really that bad on long-term follow-up? J Gastrointest Surg. 2005;9(8):1059-1067.

patient perspectives such as quality of life, adherence and satisfaction The manuscript management system is completely online and includes a very quick and fair peer-review system, which is all easy to use. Visit http://www.dovepress.com/testimonials.php to read real quotes from published authors. 